\title{
Analysis of Portuguese language blogs about bariatric surgery: key doubts of internauts regarding the postoperative period
}

\author{
Lívia Moreira Barros ${ }^{1} \cdot$ Natasha Marques Frota ${ }^{1}$ Thiago Moura de Araújo ${ }^{2} \cdot$ Michelle Tellez $^{3}$. \\ Heloisa Helena Peres Ciqueto ${ }^{4}$. Joselany Áfio Caetano ${ }^{5}$
}

Received: 30 June 2016 / Accepted: 13 November 2017

(c) Springer International Publishing AG, part of Springer Nature 2017

\begin{abstract}
Background The Internet, particularly blogs have become an important tool for patients to disseminate and exchange information on a variety of health topics, including bariatric surgery. By virtue of its interactivity being free of judgement from health care providers, blogs expose gaps in patients' knowledge and understanding.

Purpose This study analyzes the main doubts expressed in blogs by patients in the postoperative period of bariatric surgery. Method This is a qualitative exploratory study of 11 blogs of patients, who underwent bariatric surgery, that were available on the Internet between October 2013 and May 2017. The data were collected through a structured instrument and analyzed according to Bardin's suggestions. The sampling method used was intentional.

Results Evolution of diet, weight loss, plateau effect, weight regain, physical exercises, physiological changes, complications, use of contraceptive and pregnancy were the main areas of concern.

Conclusion More needs to be done to educate and prepare bariatric patients for the postoperative period. The content found in blogs serves towards building better links with patients, helps them make better decisions, and provides them an opportunity to be active participants in their own treatment.
\end{abstract}

Keywords Bariatric surgery $\cdot$ Internet $\cdot$ Information $\cdot$ Postoperative period

\section{Introduction}

More than $50 \%$ of the 693 million obese individuals in the world live in just ten countries (listed in order of number of obese individuals): USA, China, India, Russia, Brazil, Mexico, Egypt, Pakistan, Indonesia, and Germany. Brazil ranks fifth in the world with the largest absolute number of obese people in the population, the only Latin American country to be listed [1-3].

Lívia Moreira Barros

livia.moreirab@hotmail.com

1 Graduate Program in Nursing, Federal University of Ceará (UFC), Fortaleza, CE, Brazil

2 Nursing Department, University of International Integration of the Afro-Brazilian Lusophony (UNILAB), Redenção, CE, Brazil

3 University of California, East Bay, Concord, CA, USA

4 University of São Paulo (USP), São Paulo, SP, Brazil

5 Nursing Department, UFC, Fortaleza, CE, Brazil
Currently, bariatric surgery is the most effective option for the treatment of obesity and as such the procedure is occurring in greater numbers every year. The increased incidence of bariatric surgery highlights the importance of increasing awareness of the population about this treatment and its postoperative care, in order to achieve expected outcomes of lower complications, quicker response, better weight loss maintenance, lower prevalence of comorbidities, and better quality of life.

It is clear that, like the general public, obese people commonly search for information on the Internet. The Internet has become an important social environment [4] where people with similar affinities or experiencing similar situations can exchange information [5, 6]. It's estimated that $59 \%$ of adults use the Internet to get health information [7] because on the Internet, patients feel less exposed, and consequently, freer to express themselves [6].

Blogs are one of the most popular virtual interaction tools. They are discussion sites or sites with information published by individuals. Blogs allow visitors to post comments, enabling interactivity and social support. They are asynchronous 
and easy to maintain. They provide a forum in which bloggers are seen as knowledge holders, playing a crucial role in directing their readers through opinions and hyperlinks, without the watchful eyes of health care providers.

Given the perceived freedom to ask questions and express concerns, blogs are a key tool to understanding the gaps in knowledge and the fears bariatric patients experience in the perioperative period. Therefore, blog research has the potential to improving knowledge translation about this population. This study aims to learn how blogs have been used by individuals seeking bariatric surgery as treatment for obesity by analyzing their doubts about the postoperative period.

\section{Methods}

\section{Design study}

This is an observational descriptive study, with a qualitative approach, of blogs created by patients who had undergone bariatric surgery that were available on the Internet between October 2013 and May 2017.

\section{Inclusion and exclusion criteria}

The sample was found through a search of website, Blogspot. Search syntax included the following terms: "stomach reduction", "care", "postoperative", "bariatric surgery," and "blog." These terms were chosen as they are commonly used by bariatric patients. The sample inclusion criteria were: (a) created by patients who were experiencing the postoperative period of bariatric surgery, (b) between the years 2008 and 2017, (c) in Brazilian Portuguese language, (d) available for free on platform Blogspot, and (e) allowing free access. Blogs produced by health professionals or by individuals in the preoperative period were excluded.

\section{Data collection}

The data collection was done by the researcher accessing the sampled blogs. Variables were selected and coded based on a structured instrument created by Valli and Cogo in 2013 that triages information about authorship of the blog (place of origin), title, purpose, target audience, number of publications, followers and comments, last updated, content, comments, and other contacts available for clarification of doubts, which was developed to examine the theme of sexuality in adolescent blogs [4]. Sexuality, much like obesity is a topic associated with higher levels of discomfort during patient-provider interactions, and therefore, like obesity, a subject ideal for blogging. Although the instrument was not validated in field of obesity, in Brazil, or in Portuguese language, we find that the instrument offers face and content validity to attributes associated information exchange in blogs, the target of this study.

\section{Data analysis}

Data analysis was performed according to the content analysis proposed by Bardin [8], which has been validated and successfully used in several studies that evaluate communication and find indicators that infer exchange of information relative to a condition. The information contained in the blogs were collected, analyzed and disseminated without the need for authorization from authors or participants in the virtual environment, considering that the blogs are tools available in public spaces, open and accessible to any individual interested in the subject [9].

\section{Ethical considerations}

This project was approved by the Ethical Committee of the Federal University of Ceará, Brazil under CAAE 22473713.2.3001.5041. The anonymity of blog authors and participants was guaranteed, according to the copyright law number 9610 of Brazil [10]. Identifying information was coded with the name of flowers.

\section{Results}

Nine (81.8\%) blogs were created by women and two (18.2\%) by men. The age between netizens ranged from 24 to 38 years with a mean of $30.45(\mathrm{SD} \pm 4.56)$. All patients worked and lived in large cities of Brazil (54.6\% in São Paulo and 45.4\% in Porto Alegre). The average weight was $122.2 \mathrm{~kg}(\mathrm{SD} \pm 22.19)$ with minimum of $91 \mathrm{~kg}$ and maximum of $160 \mathrm{~kg}$. The mean of Body Mass Index (BMI) was $43.36 \mathrm{~kg} / \mathrm{m}^{2}(\mathrm{SD} \pm 4.73)$ with variance between 38 and $52.8 \mathrm{~kg} / \mathrm{m}^{2}$. Of the $11 \mathrm{blogs}$ evaluated, ten netizens had BMI classification as morbid obesity (grade 3 ) and one as obesity grade 2 . It was observed that all netizens performed bariatric surgery in private health services and that $18.2 \%$ (2) were submitted to surgical technique of Sleeve and 81.8\% (9) the Gastric Bypass (Table 1).

Four (36.3\%) were created in 2012, three (36.3\%) in 2011, and two (18.2\%) in 2008 and 2009, respectively. Of these, only eight $(72.7 \%)$ were being updated weekly. 


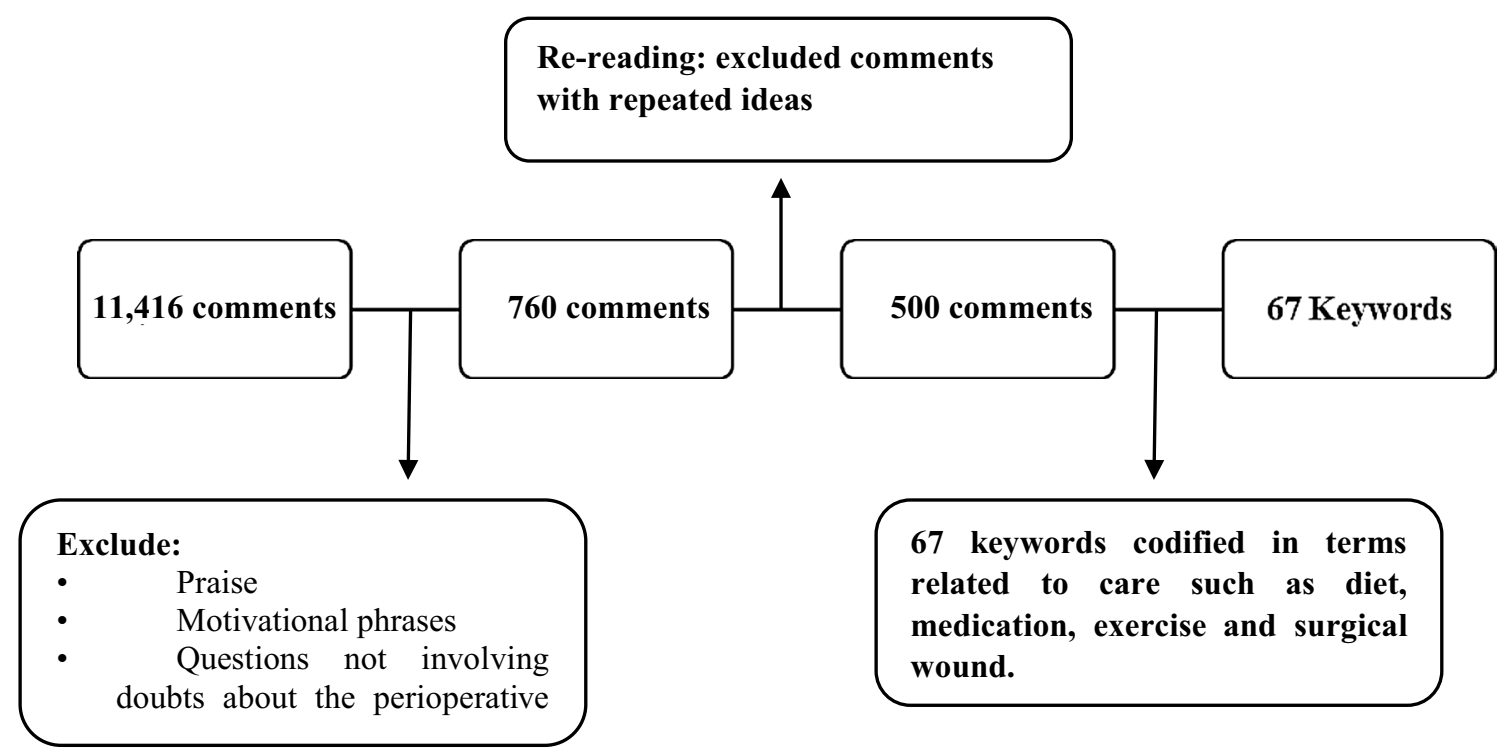

Fig. 1 Selection of comments for analysis

In the 11 blogs surveyed, 1026 posts were identified and 11,416 comments were read. From those, 760 comments were selected for further consideration. After re-reading them, 500 comments were selected for analysis and were grouped according to 67 key words, not included here, but available upon request (Fig. 1).

They were encoded, and the following categories were generated: "The virtual environment and the exchange of information", "The dietary evolution and the difficulties experienced in the postoperative period", "The fight against the balance: the weight loss and weight regained", "The fight against excess skin and the practice of physical exercises", "Physiological changes after bariatric surgery", "Bariatric surgery and the risk of complications", and "Women's health: contraception, pregnancy and childbirth after bariatric surgery".

Category 1: The virtual environment and the exchange of information.

The discovery of blogs as a possibility to share information can be observed in patients' reports:

"I decided to create a blog, to pass the time and to hold the anxiety at bay, but then I saw that this way was excellent because it would give me the opportunity to share information and receive testimonials". (Tulip) "It's amazing how we, bloggers, have similar situations, like our yearnings, our achievements, our frustrations ..." (Gardenia)

"I advise you to read a lot, ask [questions to] the operated patients, read [their] blogs, follow the people who have had the operation, their teams, and, when you are confident, seek a doctor" (Milk).
The search for information on the Internet is made, mainly, by obese people who are still in doubt about bariatric surgery as a treatment:

"I started researching on blogs about the [different] bariatric surgery techniques to mature the idea of having it done". (Sunflower)

"I' $m$ in the preoperative period and I love your blog. This helps people who, like me, have many doubts and fears about this procedure (so invasive) and that will force us to change so much!"'(Gardenia)

"Like many, I am fighting against obesity. These days. I'm thinking about bariatric surgery and I'm reading some blogs, also marking a doctor's appointment" (Violet)

"I know I will read, read and read this information together with other bloggers and friends. Thank you very much for your tips, they are invaluable" (Harpsichord)

Monitoring the evolution of weight loss through photos posted in the virtual environment encourages the followers of the blogs to get more knowledgeable about bariatric surgery and motivates them to do undertake the surgical procedure:

"I have read a lot about the subject, so that my doubts won't bother me anymore. Reading your blog has been a great incentive". (Violet)

"I' $\mathrm{m}$ in the preoperative period, and I'm trying to convince myself that surgery is not a miracle. I will reread your post a few times. You're an inspiration. Congratulations". (Orchid) 
"Well I would like to say that before doing my gastric sleeve surgery, I studied your blog a lot and that gave me the courage to continue!" (Gardenia)

Category 2: The dietary evolution and the difficulties experienced in the postoperative period.

The liquid diet phase is the most difficult. It is especially challenging to spend 15 days drinking only liquids for someone who is used to eating large quantities of food without properly chewing. Thus, preoperatively, individuals should be advised of the difficulties associated with the liquid diet phase and the subsequent evolution of the diet:

"How was it for you to have to stay one month on a liquid diet? Is it bad?" (Violet)

"Now the hardest part for me begins!!! The broths. How was that for you?" (Gardenia).

In a blog, a netizen made an inquiry about the possibility of eating pre-made soups, which are rich in sodium and low in nutrients. Others spoke about water intake. At the hospital discharge, patients should be informed about processed foods and the importance of continuing the prescribed water intake at the pre-set times to prevent dehydration.

"When will I be able to eat a broth with salt or an industrialized soup?" (Iris)

"Even when I am not thirsty, do I must consume liquids?" (Harpsichord)

"Are you drinking enough water?" (Lily).

In many blogs, the authors offer their own diets tips and their nutritionists' recipes. These suggestions encourage the readers and motivate them to vary their menus from day to day.

"Please send me your pasty food recipes. I'm going to start this phase today, and I'm going crazy" (Glass of Milk)

"Can you eat everything after surgery?" (Tulip)

"Do you look like a normal person eating?" (Sunflower)

"Do you have prioritized fruits and vegetables and avoided the sweets?" (Harpsichord).

Other questions addressed the difficulties experienced with the evolution of the postoperative diet, such as the occurrence of gagging and vomiting.

"I'm afraid of the postoperative period. I don't want to throw up or get sick. How is it after surgery?" (Orchid) "I'm still throwing up and that's really terrible. Yesterday, I couldn't eat any fruit, I threw up everything I ate. Is it like this with you?" (Iris)
Category 3: The fight for balance: weight loss and weight regained.

The high frequency of questions about weight loss highlights the importance of this issue and provides a platform for teaching. There were several comments on the kilograms lost over the months and the comparison of results between the authors and readers. A key issue is stepping on the scale, which sometimes happens daily, and can generate great anxiety. Monitoring weight over a period of 15 days or a month, is a much wiser choice.

"How often do you weigh yourself?? Do you have a good relationship with the scale?" (Tulip)

"How much weight have you lost in the first month?

And in the following months?" (Violet)

"Hi, I am 18 days postoperative, and I'm scared to death of not losing weight. Is it possible for that happen?" (Glass of milk)

The emergence of the "plateau effect" can be observed in patients' reports. Over time, there is a reduction in rate of weight loss and, at times, the weight loss stabilizes, featuring the "plateau effect".

"Every month, I have periods that my weight loss stabilizes (the famous plateau), but there are periods that my weight increases (about $1.2 \mathrm{~kg}$ ) and then I go back to losing weight. Has this ever happened to you? I'm desperate!" (Violet)

"Could it be normal to have a weight loss plateau in the very beginning? I hope you're right and that soon my body goes back to losing weight". (Glass of milk) "I'm much more peaceful knowing that there are people who lose even less than me, that means it's normal to lose a little less, right?" (Tulip)

In some blogs, the occurrence of weight regain generated tension and fear.

"What are the chances of subsequent weight gain?

How soon it is observed?" (Violet)

"Can you go back to getting fat after surgery?" (Lily)

"What do you mean regain weight? I know that those operated on can gain a little weight after 2 years, but NEVER what she weighted before the surgery. Isn't true?" (Tulip).

Patients should be made aware of the possibility of regaining the lost kilos over the years, if they do not adhere to the full treatment.

Category 4: The fight against excess skin and the practice of physical exercises.

Netizens are curious and concerned about the amount of excess skin, the type and frequency of physical exercises that are practiced by the authors of blogs, as well as the need for aesthetic treatments and plastic surgery: 
"And the hiking? You have done it? For how long?" (Daisy)

"What physical activities did you practiced after surgery and how often? What about the excess of skin, will you have reconstructive surgery?" (Orchid)

"My biggest concern is sagging. Did you go to gym or some sort of massage?" (Violet)

"Will everything sag?" (Tango).

The practice of physical activity is considered as important as the reduction of caloric intake to maintain weight loss and reduce sagging.

"Did you need plastic surgery to remove excess skin?" (Violet)

"Are you going to do some kind of plastic surgery? I got a lot of extra skin in the abdomen" (sunflower)

"Are you very flaccid? Have you ever had plastic surgery?" (Tango).

In cases where there is too much excess skin, corrective surgeries are recommended, usually 18 months after the bariatric surgery. The advantages of corrective surgeries go beyond aesthetic factors. Some patients develop low self-esteem due to excess skin, mainly in the arms and in the abdomen. Corrective surgeries can positively affect the emotional state of bariatric surgery patients.

Category 5: Physiological changes after bariatric surgery.

Because of changes in the gastrointestinal tract after surgery, there may be some changes in taste and smell, as well as changes in the odor and the consistency of stool.

"The patients in late postoperative period say that, after surgery, when they go to the bathroom to evacuate, there is a horrible smell of rotting flesh. Is this true?" (Glass of milk)

"At that stage did you feel your taste buds change? The taste of things, water, etc?" (Violet)

"Dear, did you feel any nausea, dry mouth, taste of bitterness or sour in your mouth?" (Tulip)

"After the surgery, did you have bad breath? Did it last a long time?" (Sunflower)

Some patients experience increased flatulence and halitosis, while others experience changes in body odor and perspiration. Individuals should be informed about these possibilities, so that patients are more prepared and less embarrassed, if these occur. If not addressed, these changes may lead to social isolation.

Once these alterations are identified, patients need to know about the possible treatments to reverse them. Halitosis can be improved with increased oral care and use of mouthwash; the loose stools and flatulence can be resolved with the use of medication that regulates the intestinal flora. On the other hand, changes to taste, smell, and body odor are temporary manifestations that become less accentuated when the body's metabolism stabilizes. Changes in hormone production are secondary to changes in the digestive system.

Category 6: Bariatric surgery and the risk of complications.

In the virtual environment, netizens seek information about what might happen in the postoperative period. They share their fears about the emergence of complications and surgical risk. Doubts about fistulas and pulmonary embolism, dumping syndrome, kidney stone, and psychiatric disorders, which are more frequent in the late postoperative period have been identified in blogs.

"What are the possible complications during and after surgery?" (Iris)

"I'm really scared of something going wrong, like having kidney stones (I've had it twice, it's awful). What if the stiches break, I get blood in the lungs, thrombosis, etc? Will I ever have a normal life?" (Violet)

"I feel terrible fear. I think of anesthesia, complications, fistulas, embolism ... I think about adherence... Anyhow, I'm afraid". (Gardenia)

"About the fistula, does it always need to re-operated?

Is it serious?" (Orchid)

"And the embolism? Which cases are more severe and who is more at risk" (Gardenia)

"What is dumping? Do all postop patients have it?" (Violet)

"I've read that many patients who were compulsive eater change their compulsion, they start drinking more or buy more. Is this why the psychological follow-ups are so crucial? Is this true?" (Iris).

Another frequent complication was the nutritional deficiency associated with anemia, weakness, and hair loss:

"My hair is falling a lot and my anemia is severe. I'm scared ... How do I improve this anemia?" (Iris)

"Did you feel this weakness?" (Lily)

"About your hair, do you think you could have done something for it to fall less?" (Violet)

"I'm scared about the hair loss. Will it fall off?" (Tulip).

Some netizens have fear of hair loss, but the hair loss is temporary, and it is most common in the first few months after surgery. In the blogs, netizens shared indications for treatments, including hair hydration and medications. However, the use of medications for alopecia should take place only after consultation with the treating physician.

Category 7: Women's health: contraception, pregnancy, and childbirth after bariatric surgery.

Women presented doubts about the use of the contraceptive, which highlights the importance of addressing family planning during the preoperative period: 
"Is the effect of the contraceptive pill reduced after surgery?" (Violet)

"What do you do about contraception?" (Lily)

"Can I keep using my contraceptive pill?" (Daisy).

Another area frequently asked by netizens was the possibility of becoming pregnant after surgery:

"Can a woman who undergoes bariatric surgery get pregnant? Should she undergo some extra care during this period?" (Violet)

"From what I've been seeing, pregnancy after bariatric surgery is becoming very common" (Orchid)

"I was afraid of damaging my dream (get pregnant).

Now after surgery, I'm just counting the time to have my baby" (Daisy).

\section{Discussion}

As the demand for bariatric surgery grows, there is an associated increase in online support groups, offering people the opportunity to share experiences and get advice [11]. Thus, many patients who think about undergoing bariatric surgery seek to learn more about the treatment on the Internet before making the decision to undergo surgical treatment or while choosing a surgeon $[12,13]$. The Internet has drastically changed access to knowledge by providing new ways for individuals to research information and communicate, especially about health $[14,15]$. Patients have ceased to be "passive recipients" and have become "active consumers" of health information [14].

The most frequent profile of those seeking health information on the Internet is: young female with a high education level and with a chronic disease. They seek information about their illness and enjoy using social networks to share experiences with other patients. This profile is similar to obese people who opt for bariatric surgery [14].

In this study, netizens sought information through blogs about the evolution of diet and the difficulties experienced peri-operably, such as gagging and dehydration, issues related to weight loss, plateau effect and the possibility to regain weight, the need for plastic surgery and exercise, the physiological changes that occur after bariatric surgery, the possible complications, the use of contraceptive, and the timing of pregnancy.

According to the self-reports posted in the blogs studied, the liquid diet phase is seen as the most difficult phase of the postoperative period. Therefore, patients must be targeted with messages that foster adherence, as it is a critical healing period for the new stomach. A concern expressed by many individuals in the preoperative period was about not being able to eat like a "normal person," go to a restaurant, or eat certain types of food. Nutritional information should be reinforced during the perioperative education, and patients need to be reassured that their dietary options will expand [16]. They should be informed that there will be restrictions at each recovery phase; however, after 6 months, patients will be able to eat everything, albeit in small portions [16-18].

Blogs served as a forum for comparison of weight loss between individuals. However, netizens should be made aware that the number of kilos lost differs among individuals due to various factors, such as surgical technique used, excess weight before surgery, age, and adherence to postoperative care $[19,20]$. Patients were concerned about the occurrence of the "plateau effect", which is the stabilization of weight loss. It is common for patients to initially experience a rapid weight loss, followed by a period of slower weight loss [11]. However, as patients reach a "plateau", they should be reassured that this effect is temporary. With continued physical activity, good nutrition, small portions size, and low levels of anxiety and stress, weight loss should return. However, if patients do not adhere to these measures, they may regain weight, and unfortunately, this occurs in $20-35 \%$ of the patients within 2 years of surgery $[19,21$, 22].

Blogs were also used as a resource for the exchange of information about different types of exercise. The virtual social networks had a positive effect on patients new to the practice of physical activity. The netizens motivated each other, resulting in the greater likelihood of patients achieving their established physical goals and greater weight loss [11]. However, rapid and extensive weight loss leads to sagging and excess skin, which can cause discomfort and distress to patients, as seen in the blogs analyzed [23-25]. Patients should be made aware that plastic surgery should not be considered before 12-24 months post-op, until patients finish losing excess weight and their metabolisms stabilize [3, 25].

Netizens also looked for information on postoperative complications and surgical risks [21, 26, 27]. The most frequent complication described in the blogs reviewed was the occurrence of nutritional deficiency, which is often proportional to the degree of malabsorption created by the surgical procedure or the extent of weight loss in the short term [18]. Patients need information about laboratory tests, nutritious meals, and vitamin supplements as a means to alleviate these complications.

The last category of doubts explored in this study related to taking oral contraceptive pills and the timing of pregnancy. Health professionals must provide preoperative counseling about family planning and contraception with a view that the absorption of oral contraceptive pills is reduced after surgery and a pregnancy before the body has stabilized can increase the risk of nutritional deficiencies $[28,29]$. 
Table 1 Socio-demographic data of the authors of the blogs

\begin{tabular}{lll}
\hline Variables & $n$ & $\%$ \\
\hline Sex & 9 & 81.8 \\
$\quad$ Female & 2 & 18.2 \\
$\quad$ Male & $30.45(\mathrm{SD} \pm 4.56)$ & \\
Age (mean) & & 54.6 \\
Cities & 6 & 45.4 \\
$\quad$ São Paulo & 5 & 81.8 \\
$\quad$ Porto Alegre & & 18.2 \\
Surgical technique & 9 & \\
$\quad$ Gastric bypass & 2 & \\
$\quad$ Sleeve & $122.2 \mathrm{~kg}(\mathrm{SD} \pm 22.19)$ & \\
Weight (mean) & $43.36 \mathrm{~kg} / \mathrm{m}^{2}(\mathrm{SD} \pm 4.73)$ & \\
BMI (mean) & & \\
\hline
\end{tabular}

The results of this study demonstrate the value of social networks to health care professionals as a way to understand the needs of patients. The study has shown, that according to the discern criteria, the quality of information exchange in blogs about bariatric surgery is low, meaning patients are at risk of reading confusing and imprecise information. However, health professionals should not ignore or suppress the search for information on the Internet, which is seen as an important source of knowledge in the decision-making process of patients [14]. They should discuss the information that patients searched for on the Internet, clarify doubts and help with the understanding and incorporation of the new information. It is important to recommend trusted sites, discuss the information gathered [30].

The potential benefits of virtual technologies are to improve adherence to behaviors favorable to weight loss are recognized [31], and therefore are seen as good resources for patients undergoing bariatric surgery [11]. Users reveal that blogs enables the exchange of support and motivation, creating a sense of "community" among the participants [32]. Health professionals must therefore get to know these tools in order to expand their ability to support patients and their families, either in person or virtually. When the information obtained on the Internet is used properly, patients, family members, and professionals can be benefited.

\section{Limitations}

There are several limitations to this study. The choice of blogs in Portuguese language only, bringing to question the validity of this study outside of Brazil. Future studies should include other languages. This study did not separate bloggers according to the length of time since bariatric surgery, as this variable was not available to us. This study also did not evaluate the psychological aspects that influence weight loss in the postoperative period, such as anxiety or the presence of compulsive disorders, as these data were not available from reading the blogs. Finally, this study did not thoroughly evaluate the accuracy of the information exchange. Future studies should therefore attempt to collect and analyze these data.

\section{Conclusions}

The search for information in blogs allowed a vast exchange of knowledge on various topics involving bariatric surgery. It was observed that the most common doubt among netizens was regarding the postoperative period. Monitoring the weight loss of other people through the virtual environment motivated obese individuals to seek this form treatment. One of the most discussed subjects were: phases of the diet, weight loss, plateau effect, hair loss, syndrome dumping, and occurrence of nutrient deficiencies.

Although existing on the border of informality, blogs emerge as an important tool to disseminate information on bariatric surgery. Communication in the virtual environment was found to empower preoperative, postoperative and potential candidates for this type of treatment for obesity. However, information is not always accurate. With that, we find that it critical to foster strong dialogue between health professionals and patients during consultations, aiming to provide clear and accurate information about bariatric surgery and its implications on lifestyle. Effective communication can reduce anxiety and improve treatment adherence.

\section{Compliance with ethical standards}

Conflict of interest The authors declare that they have no conflict of interest.

Research involving human participants and/or animals The authors certify that this research complied with ethical standards consistent with the Helsinki declaration.

Informed consent For this type of study formal consent is not required.

\section{References}

1. Van Nieuwenhove Y, Dambrauskas Z, Campillo-Soto A, van Dielen F, Wiezer R, Janssen I et al (2011) Preoperative very low-calorie diet and operative outcome after laparoscopic gastric bypass: a randomized multicenter study. Arch Surg 146(11):1300 1305. https://doi.org/10.1001/archsurg.2011.273 
2. Ng M, Fleming T, Robinson M, Thomson B, Graetz N, Margono C, Mullany EC et al. (2014) Global, regional, and national prevalence of overweight and obesity in children and adults during 1980-2013: a systematic analysis for the Global Burden of Disease Study 2013. Lancet 384(9945):766-81. https://doi. org/10.1016/S0140-6736(14)60460-8

3. Kubik JF, Gill RS, Laffin M, Karmali S (2013) The impact of bariatric surgery on psychological health. J Obes 1:1-5. https:// doi.org/10.1155/2013/837989

4. Valli GP, Cogo ALP (2013) School blogs about sexuality: an exploratory documentary study. Rev Gaúcha Enferm 34(3):31-37. https://doi.org/10.1590/S1983-14472013000300004

5. Edward GM, Naald NV, Oort FJ, de Haes HC, Biervliet JD, Hollmann MW et al (2011) Information gain in patients using a multimedia website with tailored information on anaesthesia. Br J Anaesth 206(3):319-324. https://doi.org/10.1093/bja/aeq360

6. Barros BR, Sousa CS, Turrini RNT (2013) Knowledge of Internet-using patients about the perioperative period of orthognathic surgery. J Nurs Educ Pract 3(12):93-102. https://doi.org/10.5430/ jnep.v3n12p93

7. Fox S, Duggan M. Health online 2013. Available at: http://www. pewinternet.org/2013/01/15/health-online-2013/. Accessed 10 May 2016

8. Bardin L (2011) Análise de conteúdo, 70 edn. São Paulo (BR)

9. Fragoso S, Recuero R, Amaral A (2011) Métodos de Pesquisa para Internet. Sulina, Porto Alegre-BR

10. Brazil (1998). Lei n. 9.610, de 19 de fevereiro de 1998: altera, atualiza e consolida a legislação sobre direitos autorais e dá outras providências. Brasília (BR)

11. Cranwell J, Seymour-Smith S (2012). Monitoring and normalising a lack of appetite and weight loss. A discursive analysis of an online support group for bariatric surgery. Appetite 58(3):873881. https://doi.org/10.1016/j.appet.2012.01.029

12. Metcalf BN (2012) Comment on: On-line bariatric surgery information session as effective as in-person information session. Surg Obes Relat Dis 8(2):229. https://doi.org/10.1016/j. soard.2011.11.003

13. Eaton L, Walsh C, Magnuson T, Schweitzer M, Lidor A, Nguyen $\mathrm{H}$ et al (2012) On-line bariatric surgery information session as effective as in-person information session. Surg Obes Relat Dis 8(2):225-229. https://doi.org/10.1016/j.soard.2011.10.015

14. Paolino L, Genser L, Fritsch S, De' Angelis N, Azoulay D, Lazzati A (2015) The web-surfing bariatic patient: the role of the internet in the decision-making process. Obes Surg 25(4):738-43. https:// doi.org/10.1007/s11695-015-1578-x

15. Conceição EM, Machado PP, Vaz AR, Pinto-Bastos A, Ramalho S, Silva C et al (2016) APOLO-Bari, an internet-based program for longitudinal support of bariatric surgery patients: study protocol for a randomized controlled trial. Trials 1 17(1):114. https:// doi.org/10.1186/s13063-016-1246-z

16. Shannon C, Gervasoni A, Williams T (2013) The bariatric surgery patient-nutrition considerations. Aust Fam Phys 42(8):547-552. http://www.racgp.org.au/afp/2013/august/the-bariatric-surgerypatient. Accessed 20 Apr 2016

17. Tariq N, Chand B (2011) Presurgical evaluation and postoperative care for the bariatric patient. Gastrointest Endosc Clin N Am 21(2):229-240. https://doi.org/10.1016/j.giec.2011.02.010
18. Rickers L, McSherry C (2012) Bariatric surgery: nutritional considerations for patients. Nurs Stand 26(49):41-48. https://doi. org/10.7748/ns2012.08.26.49.41.c9235

19. Vilchez López FJ, Campos Martín C, Amaya García MJ, Sánchez Vera P, Pereira Cunill JL (2013). Very low calorie diets in clinical management of morbid obesity. Nutr Hosp 28(2):275-285. https:// doi.org/10.3305/nh.2013.28.2.6285

20. Ochner CN, Jochner MC, Caruso EA, Teixeira J, Xavier Pi-Sunyer F (2013) Effect of preoperative body mass index on weight loss after obesity surgery. Surg Obes Relat Dis 9(3):423-427. https:// doi.org/10.1016/j.soard.2012.12.009

21. Neff KJ, Le Roux CW (2013) Bariatric surgery: a best practice article. J Clin Pathol 66(2):90-98. https://doi.org/10.1136/ jclinpath-2012-200798

22. Wedin S, Madan A, Correll J, Crowley N, Malcolm R, Karl Byrne $\mathrm{T}$ et al (2014) Emotional eating, marital status and history of physical abuse predict 2-year weight loss in weight loss surgery patients. Eat Behav 15(4):619-624. https://doi.org/10.1016/j. eatbeh.2014.08.019

23. Kalarchian MA, Marcus MD, Courcoulas AP, Cheng Y, Levine MD, Josbeno D (2012) Optimizing long-term weight control after bariatric surgery: a pilot study. Surg Obes Relat Dis 8(6):710-715. https://doi.org/10.1016/j.soard.2011.04.231

24. Groven KS, Råheim M, Engelsrud G (2013) Dis-appearance and dys-appearance anew: living with excess skin and intestinal changes following weight loss surgery. Med Health Care Philos 16(1):507-523. https://doi.org/10.1007/s11019-012-9397-5

25. Warholm C, Øien AM, Råheim M (2014) The ambivalence of losing weight after bariatric surgery. Int J Qual Stud Health Wellbeing 29(9): 22876. https://doi.org/10.3402/qhw.v9.22876

26. O'Neill T, Allam J (2010) Anaesthetic considerations and management of the obese patient presenting for bariatric surgery. Curr Anaesth Crit Care 21(1):16-23. https://doi.org/10.1016/j. cacc.2009.10.006

27. Nguyen N, Champion JK, Ponce J, Quebbemann B, Patterson E, Pham B et al (2012) A review of unmet needs in obesity management. Obes Surg 22(6):956-966. https://doi.org/10.1007/ s11695-012-0634-z

28. Armstrong C (2010) ACOG guidelines on pregnancy after bariatric surgery. Am Fam Phys 81(7):905-906. https://doi.org/10.1097/ AOG.0b013e3181ac0544

29. Sheiner E, Willis K, Yogev Y (2013) Bariatric surgery: impact on pregnancy outcomes. Curr Diab Rep 13(1):19-26. https://doi. org/10.1007/s11892-012-0329-9

30. Martins MP, Abreu-Rodrigues M, Souza JR (2015) The use of the internet by the patient after bariatric surgery: contributions and obstacles for the follow-up of multidisciplinary monitoring. Arq Bras Cir Dig 1(28 Suppl):46-51. https://doi.org/10.1590/ S0102-6720201500S100014

31. Coons MJ, Roehrig M, Spring B (2011) The potential of virtual reality technologies to improve adherence to weight loss behaviors. J Diabetes Sci Technol. 5(2):340-344. http://www.ncbi.nlm. nih.gov/pmc/articles/PMC3125926. Accessed 20 April 2016

32. Connor K, Brady RRW, Tulloh B, De Beaux A (2013) Smartphone applications (Apps) for bariatric surgery. Obes Surg 23(10):16691672. https://doi.org/10.1007/s11695-013-0950-y 